\title{
VISTORIA PATOLÓGICA: EVIDENCIAÇÃO DE MANIFESTAÇÕES PRESENTES EM EDIFICAÇÃO RESIDENCIAL
}

\author{
ROCHA, FABÍOLA LUANA MAIA \\ Professora do ensino superior \\ Universidade Federal Rural do Semi-Árido \\ Rio Grande do Norte; Brasil \\ fabiola.rocha@ufersa.edu.br
}

\author{
QUEIROZ, JOSÉ HENRIQUE MACIEL DE \\ Professor do ensino superior \\ Universidade Federal Rural do Semi-Árido \\ Rio Grande do Norte; Brasil \\ jose.queiroz@ufersa.edu.br
}

\section{RESUMO}

As manifestações patológicas são caracterizadas como um dos principais problemas a ser combatido na construção civil. As fissuras e fendas podem comprometer tanto a resistência estrutural das edificações, como traz insegurança aos usuários devido a aparência de trincas. Nesse sentido, para evidenciar se as trincas e fissuras são realmente prejudicais a estabilidade da estrutura é necessário realizar vistoria detalhada no ambiente que se deseja estudar, caracterizando a passividade ou atividade das fissuras. Nessa perspectiva, o presente trabalho buscou apresentar as manifestações patológicas identificadas em uma edificação residencial no município de Pau dos Ferros/RN. Nesse sentido, realizou-uma vistoria, coletando registros fotográficos e medições das fissuras mais evidentes. Mediante a tais constatações evidenciou-se a essencialidade da vistoria realizada, a qual explicitou manifestações nos cômodos da residência, trazendo consigo a necessidade de tomar medidas corretivas.

Palavras-chave: manifestações patológicas, vistoria, fissuras.

\begin{abstract}
Pathological manifestations are characterized as one of the main problems to be tackled in construction. Cracks and cracks can compromise both the structural strength of buildings and insecurity to users due to the appearance of cracks. In this sense, to show if the cracks and cracks are really harmful to the stability of the structure, it is necessary to carry out a detailed survey in the environment to be studied, characterizing the passivity or activity of the cracks. From this perspective, the present work sought to present the pathological manifestations identified in a residential building in the city of Pau dos Ferros / RN. In this sense, a survey was carried out, collecting photographic records and measurements of the most evident cracks. Based on these findings, the essentiality of the survey was evidenced, which made manifestations manifest in the rooms of the residence, bringing with it the need to take corrective measures
\end{abstract}

Keywords: pathological manifestations, inspection, fissures

\section{INTRODUÇÃO}

A utilização do concreto armado pela civilização é um sinônimo de desenvolvimento das construções dos mais diversos tipos, sendo impossível dissociar o desenvolvimento do material com as técnicas construtivas e modelos arquitetônicos utilizados ao longo da história. A larga gama de utilização do concreto armado pode ser atribuída às suas características particulares como a facilidade de obter peças das mais variadas formas e dimensões, bem como pelos custos competitivos com os demais materiais e ampla disponibilidade dos seus constituintes.

Com isso, milhares de obras foram construídas ao longo da história com esse material de construção. As obras mais antigas, no entanto apresentavam certas características diferentes das atuais. Antigamente produziam-se concretos com baixa resistência mecânica, e consequentemente, era necessária a modelagem de estruturas com maiores dimensões, o que implica em maior rigidez e isso colaborava com a proteção da estrutura contra a ação de agentes de deterioração, ou seja, melhorava a sua durabilidade. (ANDRADE, 1997).

Como o concreto foi se desenvolvendo tecnologicamente, nos dias atuais é possível obter concretos com resistências muito maiores que aqueles de décadas atrás. Sendo assim, não é mais necessário produzir elementos com grandes 
dimensões. Esses elementos se tornaram cada vez mais esbeltos e passaram a suportar tensões muito maiores. Em consequência disso, verificou-se a perda no quesito durabilidade, pois as estruturas ficaram mais sujeitas a ação dos agentes de deterioração. (ANDRADE, 1997).

Atualmente, diversos pesquisadores tem concentrado suas pesquisas na temática de durabilidadade das estruturas de concreto armado, motivados pela necessidade de aumentar a vida útil das construções e evitar que estas venham a apresentar manifestações patológicas e condições inadequadas de serviço durante a sua utilização, tendo em vista que recentemente, muitas obras apresentaram problemas nesse quesito.

Dado o que foi exposto anteriormente, o presente trabalho possui como objetivo analisar as manifestações patológicas identificadas em uma edificação residencial com vida útil consideravelmente avançada, construída no município de Pau dos Ferros/RN, bairro Centro, Avenida Independência, indicando suas possíveis causas e soluções.

\section{REFERENCIAL TEÓRICO}

A durabilidade das estruturas de concreto armado é um tema de importância fundamental na engenharia civil, pois estudar essa durabilidade implica em desenvolver técnicas para aumentar a vida útil das edificações e evitar o surgimento de manifestações patológicas nas mesmas, o que pode gerar incômodos e insegurança em relação a estrutura.

Muitas obras apresentaram problemas de ordem patológica nas últimas décadas devido á filosofia de projeto mais antiga que levava em consideração apenas as condições de segurança e estabilidade da estrutura diante das solicitações mecânicas que eventualmente iriam atuar. Pensava-se o concreto como um material praticamente inalterável ao longo do tempo, conservando suas propriedades físicas, químicas e mecânicas, o que não ocorre na prática, visto que o ambiente construído encontra-se cada vez mais agressivo e o concreto pode sofrer consequências da ação dos agentes presentes. (ANDRADE, 1997)

Para entender melhor o que é durabilidade, toma-se algumas definições de pesquisadores da área. De acordo com Helene (2001) a durabilidade é o resultado das interações ocorridas entre a estrutura de concreto armado, o ambiente no qual ela está inserida e as condições de uso operação e manutenção. Dessa forma, percebe-se que ela não é simplesmente uma propriedade dos materiais utilizados na construção da estrutura como a armadura ou o próprio concreto. Se pensarmos em uma estrutura qualquer de concreto armado, ela poderá apresentar durabilidade no tempo bastante variável de acordo com fatores como o tipo de ambiente com o qual ela interage e a forma como a estrutura está sendo utilizada.

Já se for considerada a definição da Norma Técnica ABNT NBR 6118:2014 - Estruturas de concreto armado Procedimento, ela diz que durabilidade "consiste na capacidade de a estrutura resistir às influências ambientais previstas e definidas em conjunto pelo autor do projeto estrutural e o contratante, no início dos trabalhos de elaboração do projeto". A mesma Norma Técnica acrescenta que "as estruturas de concreto devem ser projetadas e construídas de modo que sob as condições ambientais previstas na época do projeto e quando utilizadas conforme preconizado em projeto, conservem sua segurança, estabilidade e aptidão em serviço durante o período correspondente à sua vida útil”.

Mais uma definição importante é feita por Neville (2001), para o autor, a durabilidade significa que aquela estrutura de concreto armado apresentará um desempenho contínuo satisfatório, atendendo ás finalidades para a qual foi projetada, ou melhor, significa que a estrutura se manterá com adequada resistência mecânica e condições de serviço dentro de parâmetros admissíveis durante a vida útil esperada no momento do projeto. Para que essa durabilidade seja alcançada, é necessário então que o projetista conheça as condições ambientais e de utilização previstas para aquela estrutura, assim como deve estabelecer os procedimentos executivos adequados para obtenção da qualidade requerida.

Outro conceito importante quando se avalia o estado de conservação de uma construção é o de vida útil. A Norma Técnica ISO 13823:2008 - General principles on the design of structures for durability, traz o seguinte conceito para vida útil "período efetivo de tempo durante o qual uma estrutura ou qualquer de seus componentes satisfazem os requisitos de desempenho do projeto, sem ações imprevistas de manutenção ou reparo". Já a ABNT NBR 6118: 2014, indica que vida útil é o "período de tempo durante o qual se mantêm as características das estruturas de concreto, desde que atendidos os requisitos de uso e manutenção prescritos pelo projetista e pelo construtor, conforme itens 7.8 e 25.4 , bem como de execução dos reparos necessários decorrentes de danos acidentais”. 


\section{METODOLOGIA}

Para a obtenção dos dados expostos neste trabalho, foi utiliza a metodologia do tipo exploratória com o objetivo de conhecer a atuação de interesse em seus detalhes, fornecendo assim uma visão global da problemática. Quanto à abordagem, tomou-se como qualitativa, pois os dados não foram analisados de maneira estatística e sim com base em observações, correlação entre as situações verificadas e conhecimentos de outros autores.

A coleta dos dados foi realizada através de vistorias no local da construção entre os dias 15/03/2018 e 01/04/2018. As vistorias tiveram como objetivo o levantamento de subsídios: Identificação de manifestações patológicas, registros fotográficos, relatos históricos dos moradores.

\subsection{Caracterização da edificação}

A edificação de que trata este laudo, é um imóvel residencial de médio padrão, possui 3 pavimentos, com acesso pela fachada ou pelos fundos. Está localizado na Avenida Independência, nº 585, no centro da cidade de Pau dos Ferros no Rio Grande do Norte, área urbana comercial nas margens da rodovia federal BR 405 conforme mostra a figura 01 a seguir:

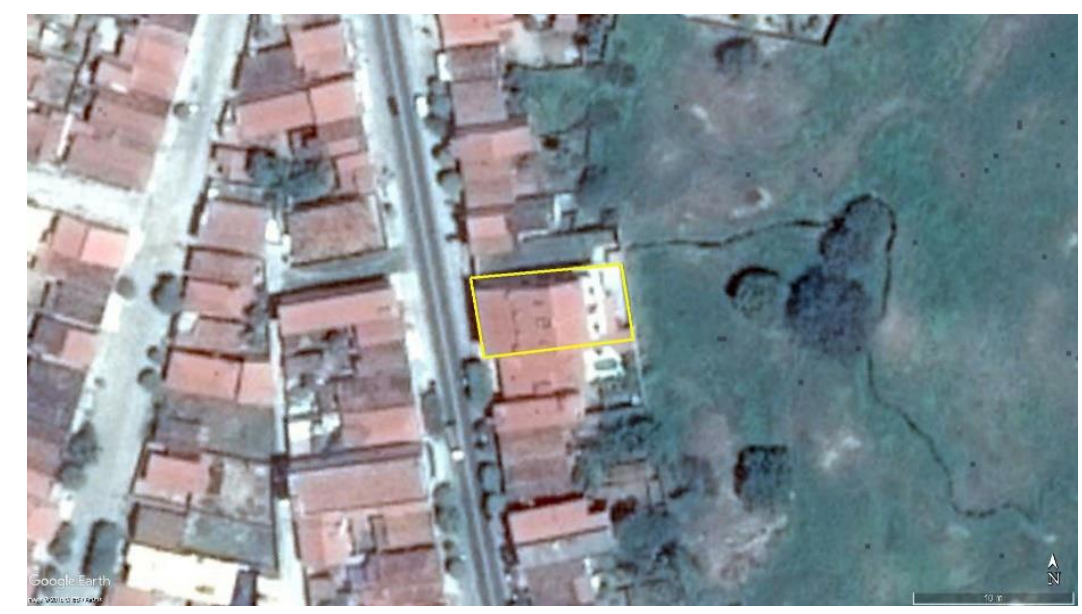

Figura 01: Imagem aérea da edificação.

Fonte: Google Earth, 2018.

Na figura 02 é mostrada também a fachada desta residência, para uma melhor identificação da mesma.

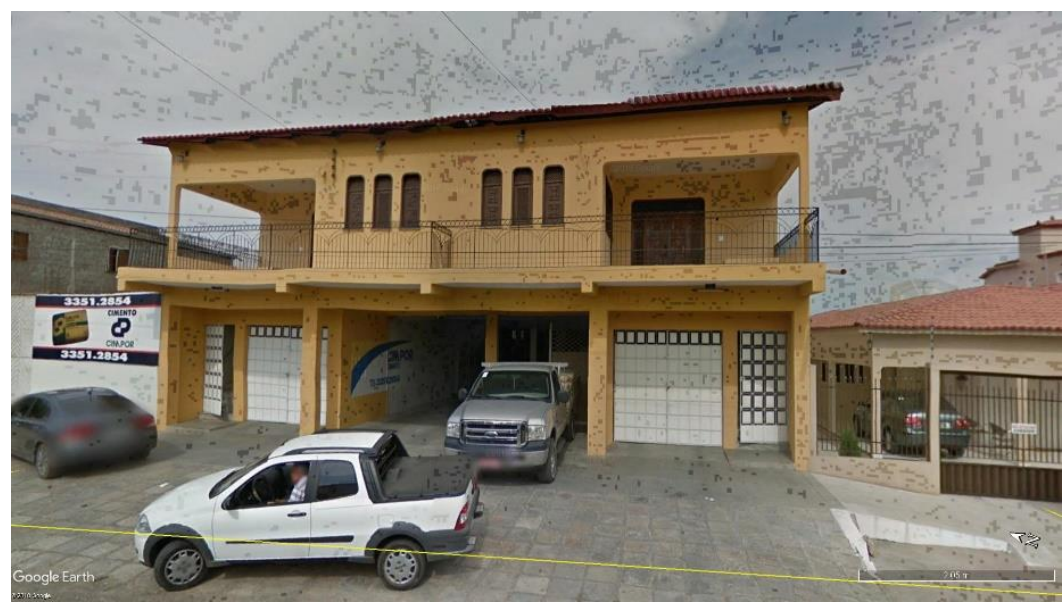

Figura 02: Fachada da edificação.

Fonte: Google Earth, 2018.

Com relação a divisão dos ambientes do imóvel, verifica-se a seguinte situação: 
No pavimento térreo encontram-se garagem, depósito e a escada de acesso ao primeiro andar. O primeiro andar, por sua vez, é composto de 2 quartos, 2 suítes, 1 cozinhas, 1 banheiros, sala, 2 varandas. Por fim o segundo andar compreende a cobertura e mais 1 quantos, 1 suítes.

Estima-se que a residência tenha sido construída a cerca de 35 anos. Neste período não foram realizadas intervenções em certos elementos que apresentam patologias, como por exemplo, vigas e lajes. Foram realizadas apenas pinturas, troca de cerâmicas em alguns cômodos e limpezas comuns.

\section{RESULTADOS E DISCUSSÕES}

A seguir são apresentadas as principais manifestações patológicas identificadas na edificação estudada. São destacados ainda os prováveis diagnósticos das patologias. As informações foram organizadas de acordo com os ambientes da casa para conferir um melhor entendimento do trabalho.

\subsection{Fachada}

Por sofrer ação mais intensa de agentes intemperes como vento, chuva, umidade, insolação, poluição do ar, dentre outros, na fachada da edificação já podem ser observadas diversas manifestações patológicas como presença de mofos e desgaste da pintura. No entanto, descreveremos aqui principalmente as patologias nos elementos estruturais .

Dos principais problemas encontrados, temos as fissuras que se formaram ao logo de quase todo comprimento da laje, principalmente nos apoios. Há inclusive na abertura destas fissuras o crescimento de pequenas vegetações como evidenciado na figura 03 a seguir.

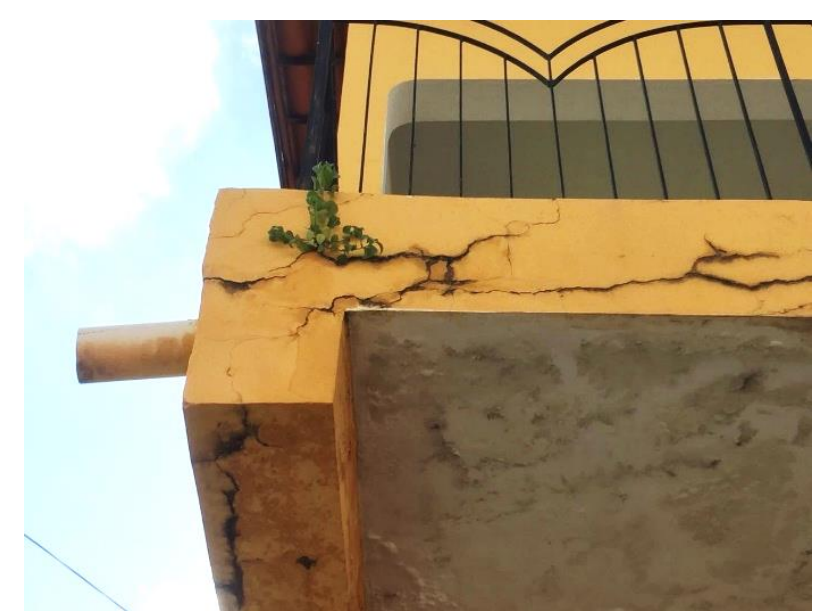

Figura 03: Fissuras na laje da varanda e crescimento de vegetação Fonte: Queiroz, 2018.

Nos pilares do pavimento térreo também foi observado o desplacamento do reboco em suas arestas, como se vê na figura 04. Possivelmente, o fato deve-se a impactos de origem desconhecida ocorridos nos pilares e a baixa aderência do revestimento ao substrato.

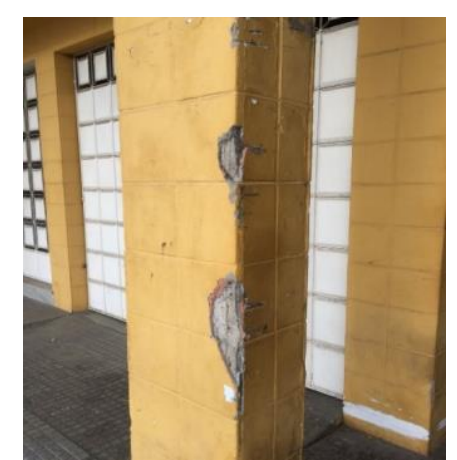

Figura 04: Desplacamento do reboco e revestimentos do pilare térreo da entrada. Fonte: Queiroz, 2018. 


\subsection{Pergolados}

Nos ambientes de circulação existem pergolados que fazem a ventilação e iluminam da casa. Estes, porém, encontramse bastante deteriorados, comprometendo além da segurança, a sua estabilidade. As pequenas vigas de concreto apresentam diversas fissuras de aberturas que variam até 8 milímetros.

Muitas destas vigas já estão com as armaduras expostas e demasiadamente corroídas, sendo que o concreto que as envolvia desprende-se, deixando-as sem o recobrimento necessário para manter a durabilidade. Na figura 05 pode ser visto de forma clara, como estas peças estavam durante as vistorias.

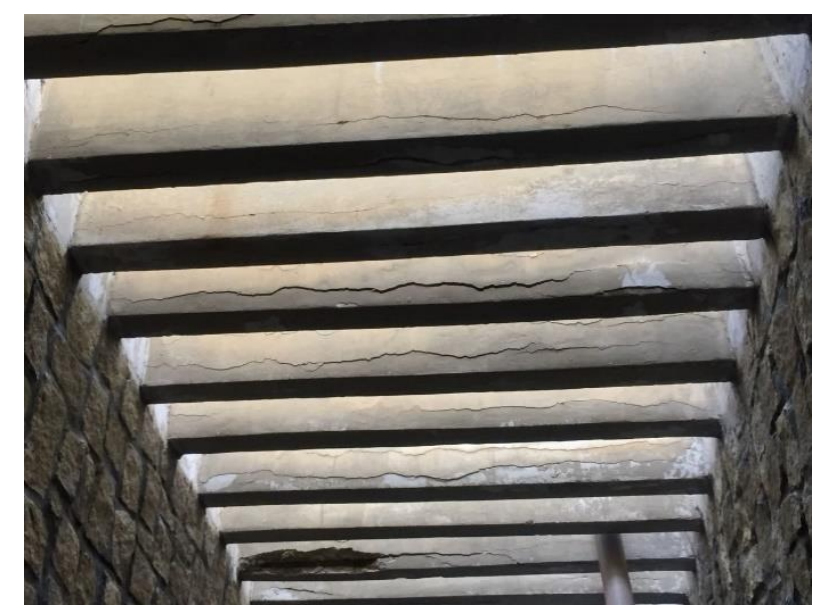

Figura 05: Vigas dos pergolados.

Fonte: Queiroz, 2018.

Esta tipologia formada, possivelmente surgiu devido a reações expansivas no interior do concreto, visto que houve o desplacamento do cobrimento das armaduras, também pode ter ocorrido pela despassivação por carbonatação do concreto, embora esta hipótese não tenha sido comprovada.

\subsection{Varanda}

Nas varandas, principalmente dos fundos da residência ( $2^{\circ}$ andar) estão presentes diversas manifestações patológicas, a iniciar pelas fissuras que se estendem por todo o revestimento do piso delas. Não foi possível verificar, todavia, se estas fissuras atingem as lajes propriamente. A figura 06 mostra parte destas fissuras. Ainda no piso, observou-se acúmulos de água, formando empoçamentos sobre as lajes.

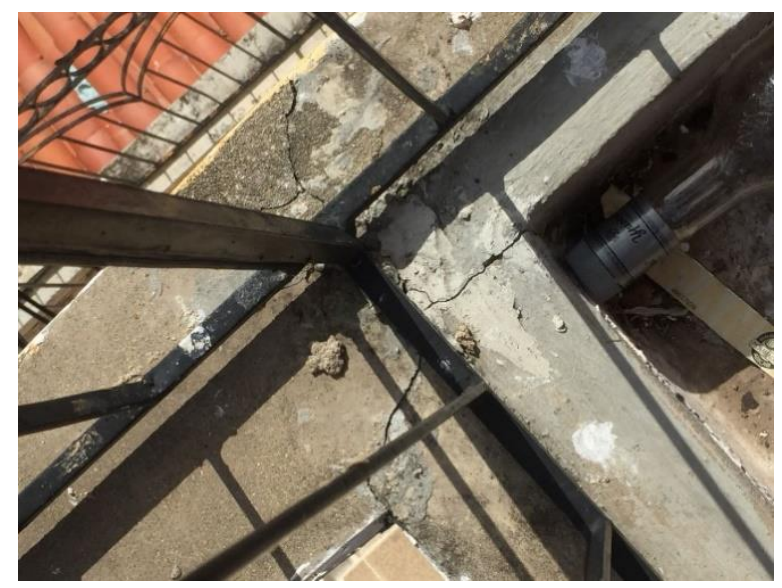

Figura 06: Piso da varanda do $2^{\circ}$ andar.

Fonte: Queiroz, 2018. 
Aparentemente a água acumulada consegue infiltrar pelas lajes e chegar a sua parte inferior, vide a Figura 07. Ainda na mesma Figura 07, se evidenciam as fissuras situadas no centro do vão das lajes, com acúmulo de mofo e material orgânico. A partir destas fissuras, nota-se sensorialmente que as armaduras possuem cobrimento de baixa espessura. Como as fissuras localizam-se no centro do vão, podem ser oriundas de carregamento excessivos.

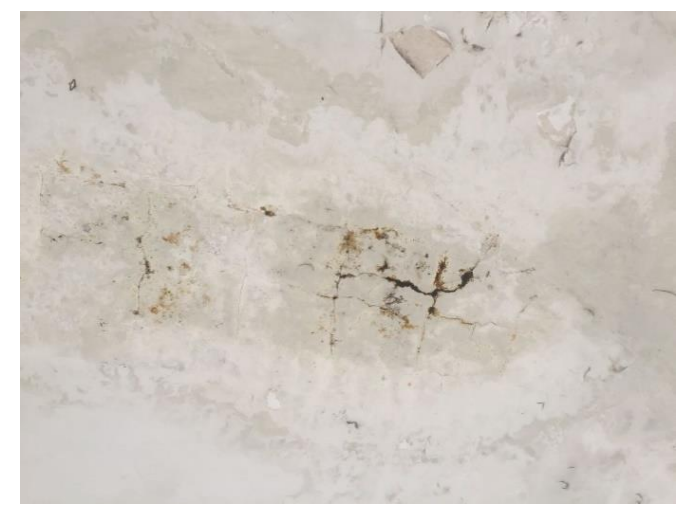

Figura 07: Fissuras e infiltração na face inferior de laje da varanda Fonte: Queiroz, 2018.

As vigas que contornam estas lajes também apresentam fissuras, principalmente nas proximidades dos apoios, conforme indica a figura 08 .

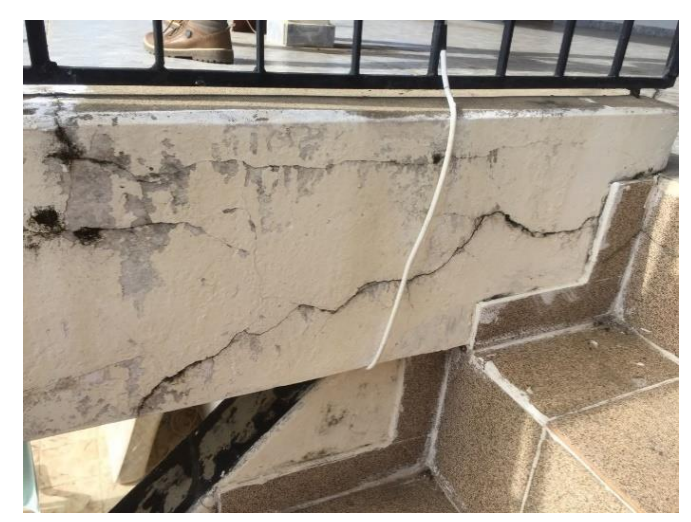

Figura 08: Fissuras em viga na lateral de laje.

Fonte: Queiroz, 2018.

Por fim, nos pilares que recebem os esforços destas vigas, também existem fissuras, algumas no sentido horizontal e outras no sentido vertical, próximas as arestas. Contudo, não foi verificado, se estas fissuras chegam a profundidades além do revestimento. A figura 09 nos dá ideia da incidência de fissuras nos pilares mencionados.

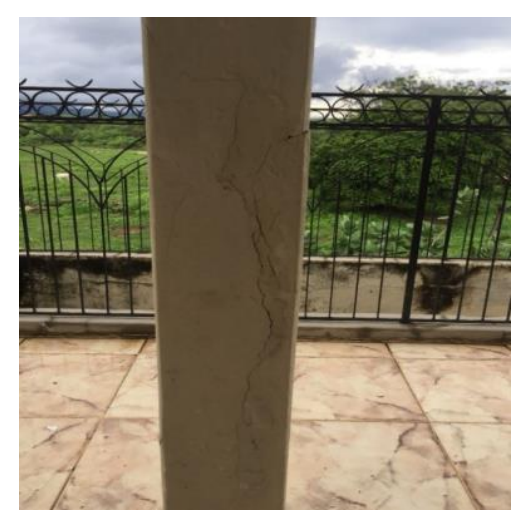

Figura 09: Pilares de sustentação da varanda.

Fonte: Queiroz, 2018. 


\section{CONCLUSÕES}

Assim, de modo geral, diversos fatores podem estar contribuindo para o surgimento das patologias aqui mostrados, pode-se citar alguns. O envelhecimento da estrutura é um fator preponderante nesse contexto, pelo relato do proprietário onde o mesmo afirma que a edificação possui mais de 35 anos chegando próximo da vida útil de um projeto estrutural, que em média dura 50 anos. Devido ao fato do proprietário ter mudado de residência há bastante tempo, a edificação não passou por manutenções periódicas apropriadas.

Somados a estes eventos citados no parágrafo anterior, a ação de intempéries e de agentes agressivos também colaboram para o surgimento das manifestações patológicas apresentadas ao decorrer do laudo. Nos elementos estruturais pode estar ocorrendo reações álcali-agregados evidenciados pela presença de fissuras das varandas, além da presença de "mofo" na cor verde. Também podem estar presentes reações de expansão nos pilares que recebem as cagas da laje e vigas das varandas; e nas pequenas vigas de concreto armado nos pergolados, pelo fato do desplacamento do concreto nestas, e nas fissuras verticais e horizontais naqueles.

Assim, as soluções para os inconvenientes encontrados são, de um modo geral, reparos nas fissuras nas alvenarias e nos elementos estruturais, porém deve ser feito outra vistoria para certificação do caráter ativo ou passivo das fissuras, pois devido à falta de equipamentos adequados não foi efetuado o teste nesse trabalho. Depois de determinar se as fissuras são ativas ou passivas parte-se para o reparo adequado das mesmas. Nas partes mais deterioradas da residência, os pilares das varandas e as vigas dos pergolados, pode-se fazer um reforço estrutural por meio de encamisamento dos pilares e vigas.

\section{REFERÊNCIAS}

ABNT (Associação Brasileira de Normas Técnicas). NBR 6118. Projeto de estruturas de concreto — Procedimento, 2014.

HELENE, P. R. L. Manual para reparo, reforço e proteção de estruturas de concreto. $2^{\mathrm{a}}$ ed - São Paulo: PINI, 1992.

NEVILLE, A. Consideration of durability of concrete structures: past, present and future. Materials and Structures. Nova Iorque, 2001.

INTERNACIONAL ORGANIZATION FOR STANDARDIZATION. ISO 13823: General principles on the design of structures for durability. England: Iso, 2008.

ANDRADE, Jair José de Oliveira. Durabilidade de Estruturas em Concreto Armado: Análise das manifestações patológicas nas estruturas no estado de Pernambuco. 1997. 139 f. Dissertação (Mestrado) - Curso de Engenharia Civil, Escola de Engenharia, Universidade Federal do Rio Grande do Sul, Porto Alegre, 1997. Disponível em: <http://www.lume.ufrgs.br/handle/10183/122441>. Acesso em: 11 jan. 2020. 